\title{
PENGARUH LAYANAN BIMBINGAN KELOMPOK MENGGUNAKAN TEKNIK MODELING UNTUK MENINGKATKAN PEMAHAMAN PERILAKU SEKS PRANIKAH SISWA KELAS XI NKPI (NAUTIKA KAPAL PENANGKAP IKAN) 1 SMK NEGERI 4 KOTA BENGKULU
}

\author{
Winda Agustin, Yessy Elita, Arsyadani Mishbahuddin \\ Prodi Bimbingan Konseling Fakultas Ilmu \\ Keguruan dan Ilmu Pendidikan Universitas Bengkulu \\ Windut424@gmail.com, yessyelita@unib.ac.id, arsyadani@unib.ac.id
}

\begin{abstract}
ABSTRAK
Penelitian ini bertujuan untuk mendeskripsikan pengaruh layanan bimbingan kelompok untuk meningkatkan pemahaman perilaku seks pranikah siswa kelas XI NKPI 1 SMK Negeri 4 Kota Bengkulu. Metode yang digunakan adalah metode eksperimen pola one grop pre-test dan post-test. Sampel dalam penelitian ini adalah siswa kelas XI NKPI 1 SMK Negeri 4 Kota Bengkulu berjumlah 7 siswa. Prosedur pengambilan sampel menggunakan purposive sampling. Teknik pengumpulan data menggunakan instrumen tes berupa soal pilihan ganda dengan aplikasi google form. Hasil penelitian menunjukkan bahwa tingkat pemahaman perilaku seks pranikah siswa sebelum diberikan layanan ratarata skor 8 dengan kategori rendah. Nilai setelah diberikam layanan rata-rata skor 20,4 dengan kategori tinggi. Hasil uji t menunjukkan nilai t 10.091 dan sig.(2-tailed) 0.000 yang berarti nilai signifikan $0.000<0,05$ sehingga $\mathrm{H}_{0}$ ditolak dan $\mathrm{H}_{\mathrm{a}}$ diterima. Artinya ada pengaruh yang signifikan terhadap tingkah pemahaman perilaku seks pranikah siswa sebelum dan sesudah diberi layanan bimbingan kelompok pada siswa kelas XI NKPI 1 SMK Negeri 4 Kota Bengkulu.
\end{abstract}

Kata kunci : Layanan Bimbingan Kelompok, Perilaku Seks Pranikah, Modelling

\section{THE INFLUENCE OF GROUP GUIDANCE SERVICES USING MODELING TECHNIQUES TO IMPROVE UNDERSTANDING OF PREMARRIED SEX BEHAVIOR STUDENTS OF CLASS XI NKPI (NAUTIKA FISHING SHIP) 1 SMK NEGERI 4 BENGKULU ABSTRACK}

This research aimed describing the effect of group counseling services to increase understanding of premarital sex behavior for the students of class XI NKPI 1 SMKN 4 bengkulu city. The method used was an experimental method with one group pre-test and post-test patterns. The sample in this study were students of class XI NKPI 1 SMK Negeri 4 Bengkulu City totaling 7 students. Purposive sampling was used as the sampling procedure. The instrument used to collect the data was a test in the form of multiple choice questions with the goggle form application. The data analysis technique used the test. The results showed that the level of understanding of students' premarital sex behavior before being given the service had an average score of 8 in the low category. The average score after being provided with service is 20.4 with high category. The $t$ test results show the $t$ value of 10.091 and sig. (2-tailed) 0.000 , which means that the significant value is $0.000<0.05$ so that $\mathrm{H} 0$ is rejected and $\mathrm{Ha}$ is accepted. This means that there is a significant effect on the level of understanding of students' premarital sex behavior before and after being given group guidance services.

Keywords : Group Counseling Service, Premarital Sex Behavior, Modelling 


\section{PENDAHULUAN}

Permasalahan pergaulan bebas sudah menjadi masalah sosial yang san 1 iaat ini belum dapat diatasi secara tuntas. Akibat yang ditimbulkan cukup serius dan tidak dapat dianggap sebagai suatu persoalan yang sederhana karena tindakan tersebut merupakan tindakan yang melanggar norma dan merugikan generasi muda bangsa. Kondisi ini sangat memprihatinkan masyarakat khususnya para orang tua dan guru, hal ini disebabkan karena pelaku dan korbannya sebagian besar adalah kaum muda dan remaja (Taher, 2012: 4). Masalah pergaulan bebas sekarang ini sudah menjadi masalah sosial yang serius. Masalah ini sangat membuat seluruh masyarakat prihatin karena banyak yang menjadi korban dan pelaku hubungan seks pra-nikah adalah remaja, yang nantinya akan menjadi kader penerus bangsa. Masa pubertas adalah periode rentan dalam perkembangan anak-anak di usia remaja.

Menurut (Mahfudzoh, 2020: 26) Faktor-faktoryang berpengaruh terhadap perilaku seksual pranikah antara lain: informasi seks lewat teknologi canggih serta media massa, kurangnya informasi mengenai seks dari orang tua dan faktor hormonal. Menurut (Hidayat, 2013: 2) Seksual dan pacaran sudah merupakan fenomena yang banyak ditemukan dikalangan remaja sekarang lemah. Adapun ciri kepribadian yang lemah tersebut antara lain, daya tahan terhadap tekanan dan tegangan rendah, harga diri yang rendah, kurang bisa mengekspresikan diri, menerima umpan balik, menyampaikan kritik, menghargai hak dan kewajiban, kurang bisa mengendalikan emosi dan agresif serta tidak dapat mengatasi masalah dan konflik dengan baik. Remaja yang sedang dalam periode ingin tahu dan ingin mencoba, akan meniru apa yang dilihatatau di dengarnya dari media massa, karena mereka belum pernah mengetahui masalah seks secara lengkap dari orang tua mereka sendiri (Suryoputro, 2006: 158).

Perkembangan jaman saat ini, ikut mempengaruhi perilaku seksual dalam Berpacaran remaja. Hal ini misalnya dapat dilihat bahwa hal-hal yang ditabukan oleh remaja pada beberapa tahun yang lalu,seperti dan bercumbu kini telah dibenarkan oleh remaja sekarang. Bahkan ada sebagian kecil dari mereka setuju dengan free sex. Kondisi tersebut Cukup mengkhawatirkan mengingat perilaku tersebut dapat menyebabkan Kasus Kehamilan Tidak Diinginkan (KTD) yang Selanjutnya memicu praktik aborsi yang tidakaman,penularan PMS dan HIV/AIDS, bahkan Kematian (Delamater, 2007: 154). Menurut Pratama (2014: 4) seks sebagai semua jenis aktifitas fisik yang menggunakan tubuh untuk mengekspresikan perasaan erotis atau perasaan. Perilaku seks pranikah 
adalah hubungan seks antara pria dan wanita meskipun tanpa adanya ikatan selama ada ketertarikan secara fisik (Nevid dkk dalam Dianawati, 2003: 3).

Bimbingan kelompok adalah salah satu dari layanan yang dimiliki oleh bimbingan dan konseling yang ada di sekolah. Dengan menggunakan bimbingan kelompok diharapkan bisa membantu siswa untuk meningkatkan pemahaman tentang bahaya seks bebas (Putri, 2013: 4) . Dalam pelaksanaannya, bimbingan kelompok dapat menggunakan teknik apapun yang dapat menjawab tujuan dari penelitian agar kegiatan bimbingan kelompok dapat menjadi lebih variatif dan berbeda dari bimbingan kelompok yang telah dilakukan di sekolah, untuk itu perlu dikembangkan model bimbingan kelompok dengan menggunakan teknik modeling. Proses teknik modeling ini bertujuan untuk membantu atau mempengaruhi tingkah laku yang lemah, teknik modeling juga memperkuat tingkah laku sebelumnya setelah siap untuk dipelajari dengan mengamati model atau perilaku teladan dari orang lain.

\section{METODE PENELITIAN}

Penelitian ini merupakan penelitian kuantitatif dengan menggunakan metode eksperimen jenis pre-eksperimen. Pre-eksperimen ditandai dengan tidak adanya variabel kontrol, dan sampel tidak dipilih secara random (Sugiyono, 2010 : 109). Desain yang digunakan adalah jenis one group pre-test dan post-test, di mana pada proses pelaksanaan penelitian hanya menggunakan satu kelompok yang nantinya akan diberikan pre-test, perlakuan dan juga post-test yang akan menjadi alat ukur seberapa berhasil perlakuan untuk meningkatkan pemahaman pendidikan seksual.

Sampel yang diambil penulis 7 siswa yang memiliki pemahaman sedang dan rendah tentang pemahaman seks pranikah. Penulis menentukan jumlah sampel 7 siswa berdasarkan jumlah peserta ideal layanan bimbingan kelompok, Teknik pengumpulan data dalam penelitian ini menggunakan tes berupa pilihan ganda skor 1 dan 0 .

Pada penelitian ini dilaukan uji validitas isi oleh tiga ahli yaitu dua orang dosen Bimbingan dan Konseling Universitas Bengkulu, dari 32 butir soal tes menjadi 22 soal, lalu dalam uji coba ini dilaukan menggunakan uji daya beda dengan bantuan SPSS versi 24.0 sehingga dari 32 soal menjadi 22 soal yang bisa digunakan. Uji reliabilitas suatu instrument maka dalam peneltian ini menggunakan rumus menggunakan teknik cronbach's alpha menggunakan program computer Statistical Packages For Social Scienes (SPSS) for windows Release 24, dengan Cronbach's alpha 0,83, maka nilai cronbach's alpha berada dikreteria reliabilitas sangat baik. 


\section{HASIL DAN PEMBAHASAN}

Berikut ini dapat dilihat tabel penentuan kategori dan perbandingan hasil pretestposttest.

Tabel 1

Penentuan Kategori

\begin{tabular}{lc}
\hline Kategori & Perhitungan \\
\hline Rendah & $\mathrm{X}<(\mathrm{M}-1 \mathrm{SD}) 0-6$ \\
Sedang & $\mathrm{M}-1 \mathrm{SD} \leq \mathrm{X}<\mathrm{M}+1$ SD 7-14 \\
Tinggi & $\mathrm{M}+1 \mathrm{SD} \leq \mathrm{X} 15-22$ \\
\hline
\end{tabular}

\section{Tabel 2}

Perbandingan Hasil pretest-posttest Skor

\begin{tabular}{ccccc}
\hline NO & Nama & Skor Pretest & Skor Postest & Peningkatan Skor \\
\hline 1 & WF & 11 & 21 & 10 \\
2 & IS & 5 & 20 & 15 \\
3 & DA & 10 & 21 & 11 \\
4 & MR & 10 & 21 & 11 \\
5 & AZ & 4 & 19 & 15 \\
6 & MF & 4 & 21 & 17 \\
7 & OH & 12 & 20 & 8 \\
\hline & Jumlah & 56 & 143 & 87 \\
\hline & Rata-rata & 8 & 20,4 & 12,4 \\
\hline
\end{tabular}

\section{Gambaran Pemahaman Tentang Perilaku Seks Pranikah Sebelum Diberikan}

\section{Layanan Bimbingan Kelompok Dengan Teknik Modelling}

Hasil yang didapat sebelum diberikan layanan bimbingan kelompok dengan teknik modelling adalah penyebaran angket dari 30 siswa diperoleh 7 siswa yang memiliki skor pemahaman seks pranikah rendah. Hal ini dapat diketahui setelah diberikan pre-test pemahaman tentang perilaku seks pranikah.

Analisis data deskriptif pretest dari 7 siswa yang mengalami pemahaman perilaku seks pranikah rendah. Siswa yang menjadi sampel dalam penelitian ini merupakan gambaran dari masalah pemahaman perilaku seks pranikah yang rendah. Berdasarkan hasil observasi wawancara kepada guru bimbingan dan konseling di sekolah bahwa materi tentang perilaku seks pranikah tidak pernah diberikan dan beberapa siswa pemahaman perilaku seks pranikahnya rendah. Untuk meningkatkan pemahaman siswa tentang perilaku seks pranikah bimbingan kelompok merupakan salah satu cara memberikan bantuan (bimbingan) kepada individu (siswa) melalui dinamika kelompok. Bimbingan kelompok dalam aktifitas dan dinamika kelompok harus diwujudkan untuk membahas 
berbagai hal yang berguna bagi pengembangan atau pemecahan masalah individu. Dalam bimbingan kelompok ini anggota kelompok harus merasa nyaman dan terbuka sehingga saat membahas suatu topik menjadi menyenangkan terutama dalam membahas perilaku seks pranikah. Layanan bimbingan kelompok akan mendorong siswa agar memahami diri sendiri, mengembangkan sikap positif, siswa akan nyaman pada dirinya sendiri .

Bimbingan kelompok dengan teknik modelling simbolis memberikan film pendek kepada siswa tentang dampak perilaku seks pranikah diusia remaja demikian dengan memberikan film tersebut siswa dapat mengerti dan memahami dampak-dampak nya mengenai perilaku seks pranikah. Pimpinan kelompok dan siswa dapat berdiskusi dan tanya jawab tentang perilaku seks pranikah.Untuk meningkatkan pemahaman tentang perilaku seks pranikah ada beberapa materi yang akan dibahas yaitu materi tentang pemahaman pergaulan bebas, perilaku seks pranikah, kurangnya pendidikan moral agama, pengaruh lingkungan sosial, perilaku seks pranikah terhadap kesehatan. Materi ini dipilih karena merupakan ilmu dasar untuk siswa dalam belajar memahami perilaku seks pranikah.

Berdasarkan hasil tersebut dapat disimpulkan bahwa masih banyak siswa yang pemahaman tentang perilaku seks pranikah masih rendah terlihat dari hasil preetest. Ketuju siswa tersebut akan diberikan perlakuan layanan bimbingan kelompok menggunakan teknik modelling simbolis .

\section{Gambaran Pemahaman Tentang Perilaku Seks Pranikah Setelah Diberikan Layanan Bimbingan Kelompok Dengan Teknik Modelling Simbolis}

Setelah diberikan layanan bimbingan kelompok dengan teknik modeling simbolis terjadi peningkatan pemahaman siswa tentang perilaku seks pranikah, hal ini terlihat dari posttes yang telah diberikan,dari tujuh siswa anggota kelompok keseluruhan skor meningkat dengan kategori tinggi. Perubahan skor tersebut meningkat setelah diberikan layanan bimbingan kelompok dengan teknik modeling simbolis yang dibahas berbagai topik tugas yang meingkatkan pemahaman perilaku seks pranikah merupakan kisi-kisi tes yang diberikan materi melalui bimbingan kelompok dengan teknik modelling simbolis. Materi yang diberikan dalam bimbingan kelompok sehingga dapat meningkatkan pemahman perilaku seks pranikah yaitu: 1. Pemahman atau pengertian pergaulan bebas, 2 . Pemahaman perilaku seks pranikah, 3. Kurangnya pendidikan moral agama, 4. Pengaruh lingkungan sosial, 5. Perilaku seks pranikah terhadap kesehatan. Teknik modeling berupa simbolis dapat digunakan sebagai salah satu cara dalam bimbingan belajar. Pimpinan 
kelompok dan siswa dapat berdiskusi dan tanya jawab tentang perilaku seks pranikah.

Pelaksanaan bimbingan kelompok yang dilakukan selama 5 kali pertemuan, anggota kelompok semakin terbuka dan tidak malu-malu lagi ketika membahas tentang perilaku seks pranikah. Pada saat pengisian posttes melalui goggle form siswa sudah sangat memahami tentang perilaku seks pranikah. Hasil posttest pemahaman tentang perilaku seks pranikah yang diberikan kepada 7 siswa dapat disimpulkan setelah diberikan perlakuan berupa bimbingan kelompok dengan teknik modeling simbolis berada dalam kategori tinggi. Hal ini menunjukkan bahwa setelah mendapatkan perlakuan berupa bimbingan kelompok dengan teknik modelling pemahaman siswa tentang perilaku seks pranikah menjadi meningkat tinggi.

\section{Pengaruh Layanan Bimbingan Kelompok Dengan Teknik Modelling Untuk Meningkatkan Pemahaman Siswa Tentang Perilaku Seks Pranikah}

Berdasarkan hasil uji hipotesis yang telah dilakukan untuk menunjukkan signifikan $0.000<0.05$ yang berdasarkan kriteria penerimaan dan penolakan hipotesis $\mathrm{H} 0$ ditolak dan Ha diterima. Maka hasil tersebut dapat disimpulkan bahwa layanan bimbingan kelompok dapat berpengaruh meningkatkan pemahaman perilaku seks pranikah siswa kelas XI NKPI 1 SMK Negeri 4 Kota Bengkulu. Dari hasil penelitian pretest dan posttest juga menunjukkan bahwa secara keseluruhan masalah rendahnya pemahaman siswa tentang perilaku seks pranikah menjadi lebih tinggi setelah mendapatkan perlakuan(treatment). Jika sebelum mendapat perlakuan bahwa hal ini diungkapkan anggota kelompok dari pengalaman bimbingan kelompok dengan teknik modelling. Siswa belum memahami pengertian pergaulan bebas, perilaku seks pranikah, dampak kurangnya moral agama, dampak lingkungan sosial, perilaku seks pranikah terhadap kesehatan. Dengan adanya bimbingan kelompok dengan teknik modelling ini siswa menjadi terbuka satu sama lain dan dapat memahami tentang perilaku seks pranikah, dapat disimpulkan bahwa pemberian bimbingan kelompok dengan teknik modelling sesuai dengan prosedur yang cukup bagus dan efektif untuk meningkatkan pemahaman perilaku seks pranikah.

Tujuan bimbingan kelompok adalah membahas suatu masalah atau topik-topik yang dirasakan menjadi kepentingan bersama. Hubungan antara anggota kelompok sangat diutamakan karena dalam layanan bimbingan kelompok semua anggota mendapatkan kedudukan yang sama untuk beradaptasi atau berinteraksi dengan anggota lainnya. Bimbingan kelompok juga bertujuan bahwa siswa untuk dapat saling mengenal satu sama lain, saling jujur dan terbuka sehingga dapat memanfaatkan dinamika kelompok. Peneliti 
memilih teknik modelling untuk meningkatkan pemahaman perilaku seks pranikah. Teknik modelling adalah proses bagaimana individu belajar dari mengamati orang lain, teknik modelling dianggap efektif untuk meningkatkan pemahaman tentang perilaku seks pranikah dan biasanya siswa malu-malu untuk membahas tentang seks tersebut. Tujuannya agar siswa mampu menjaga dirinya dari pergaulan yang tidak sehat, dan mampu meningkatkan pemahman siswa tentang seks pranikah.

Bandura, 2006: 340 (dalam bradlay, 2016) Modelling adalah proses bagaimana individu belajar dari mengamati orang lain. Modelling simbolis adalah strategi yang digunakan untuk mempeljari respon baru atau menghilangkan rasa takut di mana modelnya disajikan memalui vidio film pendek ( Abimanyu dan Manrihu, 1997: 316). Teknik Modelling sebagai strategi pencegahan masalah yang dialami oleh siswa dalam meningkatkan pemahaman perilaku seks pranikah. Berikut ini siswa yang mengalami peningkatan pemahaman perilaku seks pranikah dengan inisial WF,IS,DA,MR,AZ,MF,OH yang awalnya rendah sekarang menjadi tinggi.

Dalam bimbingan kelompok ini terdapat 5 kali pertemuan yang sudah dilakukan, anggota kelompok semakin terbuka dan nyaman dengan dinamika kelompok siswa menjadi terbuka dan tidak merasa malu lagi ketika membahas materi tentang perilaku seks pranikah. Dapat disimpulkan bahwa ada perbedaan pemahaman perilaku seks pranikah sebelum dan sesudah diberikan layanan bimbingan kelompok dengan teknik modelling pada siswa kelas XI NKPI 1 SMK Negeri 4 Kota Bengkulu. Hal ini menunjukkan bahwa layanan bimbingan kelompok dengan teknik modelling meingkatkan pemahaman siswa tentang perilaku seks pranikah. Dapat disimpulkan bahwa layanan bimbingan kelompok dapat berpengaruh untuk meningkatkan pemahaman siswa tentang perilaku seks pranikah, hal itu terlihat dari hasil peningkatan posttest.

Peningkatan pemahaman siswa tersebut sesuai dengan hasil penelitian yang dilakukan oleh Dewi (2015: 01) dengan judul penelitian "Meningkatkan Pengetahuan Pendidikan Seks Pranikah Pada Siswa Kelas VI Madrasah Ibtidayiah Negri Sumerrejo Kota Semarang” . Hasil penelitian yang diperoleh, tingkat pengetahuan siswa sebelum mendapatkan layanan informasi tergolong dalam kategori rendah dan persentasenya $39 \%$. Hasil penelitian yang saya lakukan dengan judul "Pengaruh Laynanan Bimbingan Kelompok Menggunakan Teknik Modeling Untuk Meningkatkan Pemahaman Perilaku Seks Pranikah Siswa Kelas XI NKPI 1 SMK N 4 Kota Bengkulu”. Hasil penelitian yang diperoleh tingkat pemahaman siswa sebelum diberikan perlakuan bimbingan kelompok 
dengan memberikan pemahman seks pranikah tergolong dalam kategori rendah dan persentasenya 18\%. Hasil penelitian Nur Ahmad (2013: 01) mengatakan bahwa hipotesis yang diajukan dalam penelitian ini yang berbunyi "ada perbedaan skor tingkat keinginan berperilaku seks bebas pada siswa kelas XI APK C SMK RADEN RAHMAT antara sebelum dan sesudah diberikan perlakuan konseling kelompok realita' dapat diterima. Dengan demikian penerapan konseling kelompok realita dapat mengurangi keinginan berperilaku seks bebas pada siswa SMK Raden Rahmat Mojosari. Hasil penelitian yang saya lakukan yaitu "ada perbedaan skor tingkat pemahaman perilaku seks pranikah pada siswa kelas XI NKPI 1 SMK N 4 Kota Bengkulu sebelum dan sesudah diberikan perlakuan bimbingan kelompok "dapat di terima".

\section{KESIMPULAN}

Berdasarkan dari hasil penelitian ini dapat disimpulkan bahwa pemahaman perilaku seks pranikah menggunakan layanan bimbingan kelompok terjadi peningkatan pemahaman seks pranikah. Berdasarkan uraian tersebut maka dapat disimpulkan bahwa setelah diberikan Treatment ada perubahan peningkatan yang disignifikan pemahaman perilaku seks pranikah mengikuti aktifitas bimbingan kelompok terhadap pemahman seks pranikah siswa SMK 4 Kota Bengkulu.

\section{DAFTAR PUSTAKA}

Dinawati, H.(2003). Pendidikan Seks Untuk Remaja. Jakarta: Kawan Pustaka

Pratama, Hayati, \& Suprihatin. (2014). Hubungan Pengetahuan Remaja Tentang Pendidikan Seks Deng(Hidayat, Juni 2013)an Perilaku Seks Pranikah Pada Remaja . Jurnal Keperawatan Vol.II.No.2 September 2014,

Delameter. (2007). Sexsual Behavior In Later Life. Journal Or Aging And Health, 154. Hidayat. (Juni 2013). Pengaruh Harga Diri dan Pelajar Moral Terhadap Perilaku Seksual Remaja Berpacaran . Jurnal Psikostudia Universitas Mulawarman, Vol.2.No.1, hlm.1-9.

Mahfudizoh. ( April 2020). Peningkatan Pemahaman Siswa Tentang Resiko Perilaku Seksual Pranikah. Journal Universitas PGRI Semarang Vol.7.No.1.

Putri. (2013). Penerapan Bimbingan Kelompok Teknik Homeroom Untuk Meningkatkan Pemahaman Siswa Tentang Rsiko Perilaku Seksual Pranikah e. Vol.1.No.1.

Suryoputro. (2006). Faktor-faktor yang mempengaruhi Perilaku Seksual Remaja Di Jawa Tengah Impikasi terhadap Kebijakan dab Layanan Kesehatan Seksual dan Reproduksi. Jurnal Makara, Kesehatan Vol.10.No1, 158.

Sarwono, S, \& W. (2006). Psikologi Remaja. Jakarta: PT Raja Grafindo Persada. 
Sarwono , S, \& W. (2010). Psikologi Remaja. Jakarta : Raja Grafindo Persada

Taher,J. (2012). Eco-Tropica Manado. Jurnal Jendela Ilmu. Volume 1, Nomor 22019 